\title{
Repository Corticotropin Injection for Persistently Active Systemic Lupus Erythematosus: Results from a Phase 4, Multicenter, Randomized, Double- Blind, Placebo-Controlled Trial
}

\author{
Anca D. Askanase - Enxu Zhao - Julie Zhu - Roman Bilyk · \\ Richard A. Furie
}

Received: July 30, 2020 / Accepted: September 14, 2020

(C) The Author(s) 2020, corrected publication 2021

\section{ABSTRACT}

Introduction: We assessed the efficacy and safety of repository corticotropin injection (RCI; Acthar $^{\circledR} \mathrm{Gel}$ ) for persistently active systemic lupus erythematosus (SLE) despite use of moderate-dose glucocorticoids.

Methods: This multicenter, double-blind, randomized, placebo-controlled study enrolled patients $\geq 18$ years with active SLE and moderate to severe rash and/or arthritis despite stable glucocorticoid doses $(7.5-30 \mathrm{mg} /$ day prednisone equivalent) and antimalarials for $\geq$ 4 weeks and/or immunosuppressants for $\geq 8$ weeks before screening. Stable glucocorticoid doses

Digital Features This article is published with digital features to facilitate understanding of the article. To view digital features for this article go to https://doi.org/ 10.6084/m9.figshare.12951239.

Electronic Supplementary Material The online version of this article (https://doi.org/10.1007/s40744020-00236-1) contains supplementary material, which is available to authorized users.

A. D. Askanase ( $\square)$

Columbia University Medical Center, New York, NY, USA

e-mail: ada20@cumc.columbia.edu

E. Zhao $\cdot$ J. Zhu $\cdot$ R. Bilyk

Mallinckrodt Pharmaceuticals, Bedminster, NJ, USA

R. A. Furie

Zucker School of Medicine at Hofstra/Northwell,

Hempstead, NY, USA were required through week 16 with optional taper from weeks 16 to 24 . Patients were randomized (1:1) to 80 U RCI subcutaneously or placebo every other day to week 4 , then twice weekly to week 24 . Endpoints included the proportion of SLE Responder Index (SRI)-4 responders at week 16; changes from baseline to week 16 in 28 Swollen Joint Count/Tender Joint Count (28 SJC/TJC) and Cutaneous Lupus Erythematosus Disease Area and Severity Index (CLASI)-Activity score; and changes from baseline to week 24 in inflammatory cytokines. Safety was assessed by adverse events.

Results: In the modified intention-to-treat population (RCI, $n=84$; placebo, $n=85$ ), the proportion of SRI-4 responders at week 16 was not significantly different between groups (RCI, 47.6\%; placebo, 43.5\%; OR [95\% CI] 1.2 [0.6 to 2.2]; $p=0.5762$ ). RCI treatment resulted in a reduction from baseline to week 16 in 28 SJC/TJC and CLASI-Activity score and from baseline to week 8 in $B$-cell activating factor cytokine. Post hoc analyses demonstrated a greater proportion of BILAG-based Combined Lupus Assessment responders for RCI than placebo at weeks 4, 12, and 20 and greater SRI-4 response in RCI-treated patients with baseline SLE Disease Activity Index$2000 \geq 10$ and CLASI-Activity $\geq 11$. No new safety signals were identified.

Conclusions: Despite failure to achieve the primary endpoint, these results support the utility of RCI for treating persistently active SLE. Trial Registration: ClinicalTrials.gov identifier NCT02953821. 
Keywords: Acthar Gel; Autoimmune disease; Clinical trial; Corticosteroid; Glucocorticoid; Inflammation; Repository corticotropin injection; Systemic lupus erythematosus

\section{Key Summary Points}

\section{Why carry out this study?}

Repository corticotropin injection (RCI; Acthar ${ }^{\circledR}$ Gel) is currently approved for use during exacerbations and as maintenance therapy for systemic lupus erythematosus (SLE).

Findings from a prospective phase 4 study and subsequent post hoc analyses suggested that RCI is safe and may be effective for treating patients who have persistently active SLE despite treatment with moderate-dose glucocorticoids.

These results provided the basis for further evaluation in this larger, multicenter, double-blind, randomized, placebocontrolled study of the safety and efficacy of RCI for the treatment of persistently active SLE.

\section{What was learned from the study?}

Treatment with RCI was associated with improvements of several clinical and pharmacodynamic endpoints: 28 Swollen Joint Count/Tender Joint Count, Cutaneous Lupus Erythematosus Disease Area and Severity Index-Activity (CLASIActivity) scores, and levels of $B$-cell activating factor cytokine. Post hoc analyses demonstrated a greater proportion of British Isles Lupus Assessment Groupbased Combined Lupus Assessment (BICLA) responders for RCI than for placebo and greater SLE Responder Index (SRI)-4 response in RCI-treated patients with baseline SLE Disease Activity Index$2000 \geq 10$, CLASI-Activity $\geq 11$, British Isles Lupus Assessment Group-2004 $\geq 20$, and complement component $4<17 \mathrm{mg} / \mathrm{dl}$ than in patients with lower disease activity.
The favorable BICLA response observed with RCI for the entire population in combination with benefits seen with SRI-4 in patients with high levels of baseline disease activity support the value of RCI for the treatment of persistently active SLE despite background glucocorticoids.

\section{DIGITAL FEATURES}

This article is published with digital features to facilitate understanding of the article. To view digital features for this article go to https://doi. org/10.6084/m9.figshare.12951239.

\section{INTRODUCTION}

Systemic lupus erythematosus (SLE) is an autoimmune disease characterized by inflammation that leads to organ damage and premature death [1]. Multiple factors guide therapeutic decisions in SLE, including disease severity, comorbidities, and the affected organs $[2,3]$. Despite treatment that includes nonsteroidal anti-inflammatory drugs (NSAIDs), glucocorticoids, antimalarials, and immunosuppressants, there exists a great unmet need in SLE for more efficacious and safer therapies [3].

Repository corticotropin injection (RCI; Acthar ${ }^{\circledR}$ Gel) is approved by the United States Food and Drug Administration for use during an exacerbation or as maintenance therapy in SLE [4]. RCI is a naturally sourced complex mixture of adrenocorticotropic hormone analogues and other pituitary peptides that interacts with all five melanocortin receptors, resulting in the activation of several anti-inflammatory pathways through both glucocorticoid-dependent and glucocorticoidindependent mechanisms [5-9].

The effectiveness of RCI for the treatment of SLE has been demonstrated in previous clinical studies [10-12]. Findings from a pilot study [11] and subsequent post hoc analyses [12] suggested that RCI is safe and may be effective for treating patients who have persistently active SLE despite treatment with moderate-dose 
glucocorticoids. These results provided the impetus for further evaluation of RCI in a larger study of SLE.

The purpose of the current multicenter, randomized, double-blind, placebo-controlled trial was to provide additional data regarding the efficacy and safety of RCI in the treatment of SLE. The objective was to assess the ability of RCI to reduce SLE disease activity in patients who have persistently active SLE despite treatment with moderate-dose glucocorticoids.

\section{METHODS}

\section{Ethics and Compliance}

The study protocol was approved by the Western Institutional Review Board centrally and by the local ethics committees/institutional review boards at individual study sites. The study was conducted in accordance with the Declaration of Helsinki and requirements of clinical trials registration (ClinicalTrials.gov identifier NCT02953821). Written informed consent from patients was required.

\section{Patients}

This multicenter, randomized, double-blind, parallel-group, placebo-controlled study was conducted across 54 study sites in Argentina, Chile, Mexico, Peru, and the US. The study design has been described in detail previously [13]. Investigators enrolled adults aged $\geq 18$ years with active SLE $(\geq 4$ of 11 American College of Rheumatology criteria [14]; SLE Disease Activity Index-2000 [SLEDAI$2 \mathrm{~K}$ ] [15] score $\geq 6$ at screening; and clinical SLEDAI-2K [excluding laboratory results] score $\geq 4$ at both screening and randomization) and with moderate to severe rash and/or arthritis by British Isles Lupus Assessment Group-2004 (BILAG-2004) [16] scores A or B in the mucocutaneous or musculoskeletal domains at both screening and randomization. Patients were permitted to enroll if they were on glucocorticoids for at least 8 weeks prior to screening and were receiving stable glucocorticoid doses of
7.5-30 mg of daily prednisone equivalents for at least 4 weeks before screening. The use of topical and/or inhaled glucocorticoids during the study period was allowed. Patients were also permitted to enroll if they were on stable doses of antimalarials or NSAIDs for at least 4 weeks and/or immunosuppressants for at least 8 weeks before screening; however, taking NSAIDs and/ or immunosuppressants was not a condition for inclusion. We excluded patients with severe active lupus nephritis (serum creatinine $>2.5 \mathrm{mg} / \mathrm{dl}$, proteinuria $>1.5 \mathrm{~g} / \mathrm{g}$, or requiring hemodialysis within 3 months before screening) or with active central nervous system manifestations of lupus within 3 months before screening or between screening and first dose of study drug.

\section{Randomization and Masking}

Block randomization using a computer-generated allocation scheme was used to assign patients (1:1) to receive RCI or placebo. Randomization was stratified by location (US or outside US) and glucocorticoid dose (prednisone or equivalent $\leq 20 \mathrm{mg}$ per day and $>20 \mathrm{mg}$ per day). Both patients and investigators were blinded to study treatment assignments, with subject identification numbers to facilitate blinding.

\section{Procedures}

Patients or their caregivers administered $80 \mathrm{U}$ of RCI or matching placebo subcutaneously every other day for 4 weeks, then twice per week for an additional 20 weeks. Treatment compliance was monitored using study drug diaries. Patients were encouraged to taper their glucocorticoid doses between weeks 16 and 24 when clinically appropriate at the discretion of the investigator. Doses of all other background antimalarials, NSAIDs, and immunosuppressants remained stable throughout the study. The following assessments were performed through study week 24: BILAG-2004; Cutaneous Lupus Erythematosus Disease Area and Severity Index (CLASI)-Activity [17]; Physician Global Assessment (PGA) [18]; Safety of Estrogens in 
Lupus Erythematosus National Assessment (SELENA) Flare Index [19]; SLEDAI-2K; and 28 Swollen Joint Count/Tender Joint Count (28 SJC/TJC). The BILAG-2004 Index was assessed over a 4-week period, and total scores were the sum of scores from all nine organ systems in the BILAG questionnaire using the coding scheme of $A=12, B=8, C=1$, and $D / E=0$ [20]. SLEDAI-2K was assessed over a 10-day window, and total scores were the sum of all weighted scores of all 24 manifestations in the index. After baseline, visits for evaluations were conducted at weeks $2,4,6,8,12,16,20,24$ (or early termination), and 28 (follow-up).

\section{Outcomes}

The primary endpoint was the proportion of SLE Responder Index (SRI)-4 responders in the RCI-treated group compared with the proportion of SRI-4 responders in the placebo group at week 16. An SRI-4 responder was defined as a patient with a four-point reduction from baseline in the SLEDAI-2K, with no new BILAG A score and no more than one new BILAG B organ domain score compared with baseline, and with $\mathrm{a} \leq 10 \%$ increase from baseline in PGA [21]; patients who did not provide data to allow for classification as a responder were considered non-responders. Secondary endpoints included the change from baseline to week 16 in the following assessments: SLEDAI-2K; BILAG-2004; PGA; CLASI-Activity; and 28 SJC/TJC (comprising those joints that were both tender and swollen). Secondary endpoints also included the time to first treatment response as assessed by the SRI- 4 and the proportion of patients with a decrease of at least four points in the SLEDAI$2 \mathrm{~K}$ at week 16 . The following exploratory endpoints were evaluated: decrease from baseline in daily glucocorticoid dose during week 17 to week 24; proportion of patients at week 24 with a decrease in prednisone equivalent to $<7.5 \mathrm{mg}$ per day and by $>50 \%$ compared with baseline; proportion of SRI-4 responders at week 16 that maintained response through week 24 ; proportion of patients with a decrease of at least four points in the SLEDAI-2K at week 24; and changes from baseline in levels of cytokines, circulating lymphocytes, and bone turnover markers through week 24. Post hoc analyses assessed the percent of baseline over time through week 24 for B-cell activating factor (BAFF) cytokine. Safety outcomes included adverse events (AEs) and serious AEs (SAEs) assessed throughout the study.

In post hoc analyses, we determined the proportion of BILAG-Based Combined Lupus Assessment (BICLA) responders, defined as patients meeting the following criteria: at least one gradation of improvement in baseline BILAG scores in all body systems with moderate or severe disease activity at entry (i.e., all $\mathrm{A}$ scores falling to B, C, or D and all B scores falling to $C$ or D); no new BILAG A scores or no more than one new BILAG B score; no worsening of total SLEDAI-2K score from baseline; no significant deterioration $(\leq 10 \%$ increase from baseline) in PGA; and no treatment failure (e.g., initiation of non-protocol treatment) [22]. Patients who did not provide data to allow for classification as BICLA responders were considered non-responders.

We also performed a post hoc regression tree analysis to detect the variables that were predictive of an SRI-4 response. The following variables were identified as predictive baseline characteristics and were stratified in subgroup analyses for proportion of SRI-4 responders: baseline SLEDAI-2K score $(<10$ vs. $\geq 10)$; CLASI-Activity score ( $<11$ vs. $\geq 11$ ); BILAG2004 score $(<20$ vs. $\geq 20)$; historical versus baseline antinuclear antibody (ANA), anti-double-stranded DNA (anti-dsDNA) antibody, or extractable nuclear antigen (ENA) antibody tests; baseline ANA $(<1: 80$ vs. $\geq 1: 80)$; and baseline complement component 4 $(\mathrm{C} 4,<17 \mathrm{mg} / \mathrm{dl}$ vs. $\geq 17 \mathrm{mg} / \mathrm{dl})$. Patients who did not provide data to allow for classification as SRI-4 responders were considered nonresponders.

\section{Statistical Analysis}

Primary, secondary, exploratory, and post hoc efficacy endpoints were analyzed in the modified intention-to-treat (mITT) population, defined as patients who received at least one 


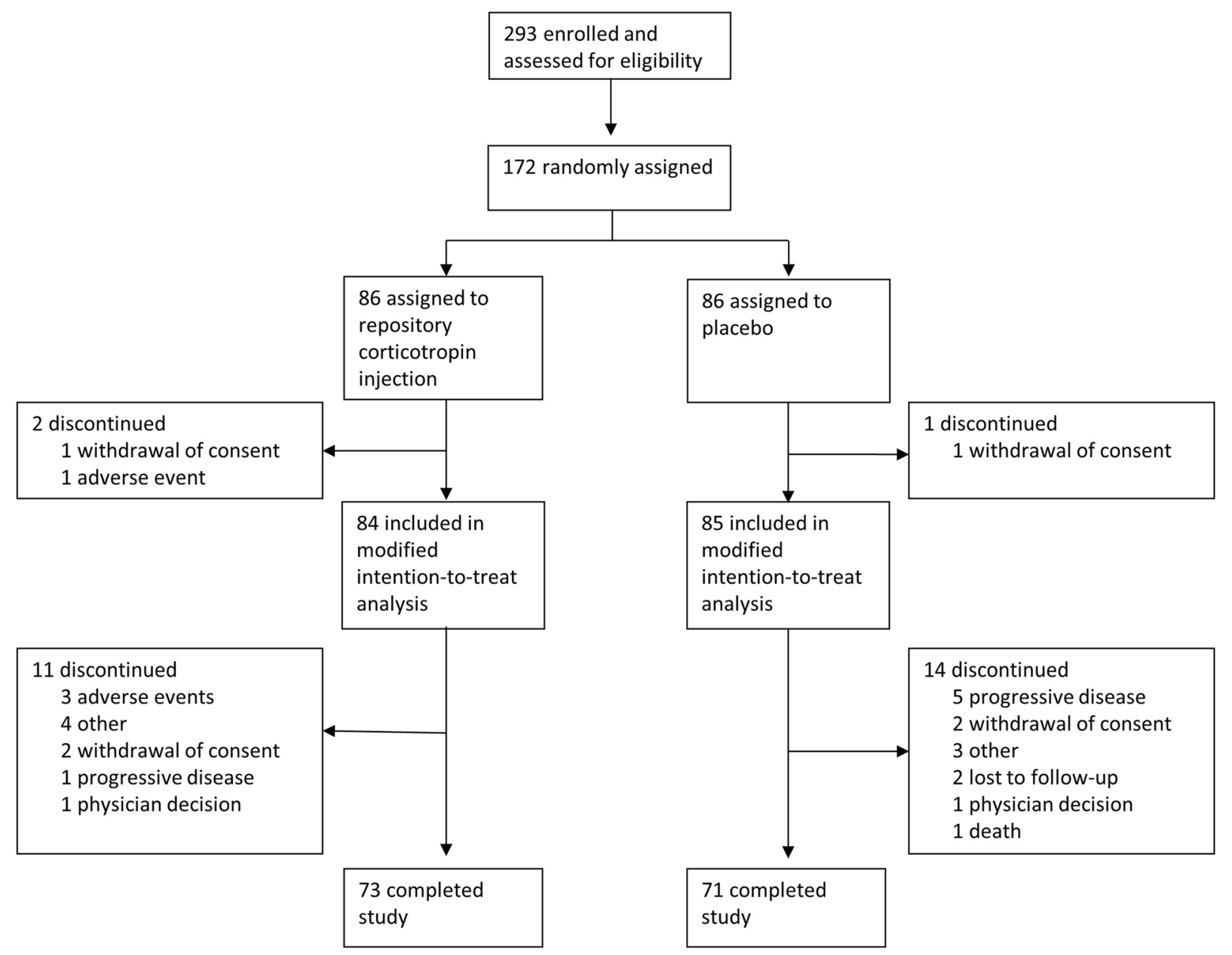

Fig. 1 Trial profile

dose of study drug and contributed any postbaseline efficacy data. With assumed SRI-4 response rates of $30 \%$ in the placebo group and $55 \%$ in the RCI group, a sample size of 80 patients per treatment group was determined to provide $90 \%$ power to demonstrate statistical significance for the primary endpoint with a significance level of 0.05 . The primary endpoint was assessed using a Cochran-Mantel-Haenszel test, with strata corresponding to the stratification factors used for randomization (location [US and outside the US] and baseline glucocorticoid dose $[\leq 20$ and $>20 \mathrm{mg}$ per day]). Secondary and exploratory endpoints that were based on proportions of patients were analyzed using the same statistical method as for the primary endpoint. Quantitative endpoints were analyzed using analysis of covariance models with the change from baseline as the dependent variable, treatment as the factor, and baseline value of the corresponding endpoint as the covariate and were stratified for the same factors used for randomization. Time-to-response endpoints were analyzed using a log-rank test. Safety endpoints were assessed in the safety population (all patients who received at least one dose of study drug) and were summarized descriptively. Analyses were performed using SAS 9.4 (SAS Institute Inc.). 
Table 1 Baseline demographics and patient characteristics of the mITT population

\begin{tabular}{|c|c|c|}
\hline & $\begin{array}{l}\text { RCI } \\
(n=84)\end{array}$ & $\begin{array}{l}\text { Placebo } \\
(n=85)\end{array}$ \\
\hline Age, years, mean (SD) & $\begin{array}{l}40.1 \\
\quad(12.3)\end{array}$ & $39.2(13.1)$ \\
\hline \multicolumn{3}{|l|}{ Gender, no. (\%) } \\
\hline Male & $10(11.9)$ & $4(4.7)$ \\
\hline Female & $74(88.1)$ & $81(95.3)$ \\
\hline \multicolumn{3}{|l|}{ Race, no. (\%) } \\
\hline Caucasian & $33(39.3)$ & $30(35.3)$ \\
\hline African American & $9(10.7)$ & $8(9.4)$ \\
\hline American Indian or Alaska Native & $18(21.4)$ & $18(21.2)$ \\
\hline Other & $24(28.6)$ & $29(34.1)$ \\
\hline \multicolumn{3}{|l|}{ Ethnicity, no. (\%) } \\
\hline Hispanic or Latino & $66(78.6)$ & $70(82.4)$ \\
\hline \multicolumn{3}{|l|}{ Location, no. (\%) } \\
\hline US & $28(33.3)$ & $28(32.9)$ \\
\hline Outside of US & $56(66.7)$ & $57(67.1)$ \\
\hline Weight, kg, mean (SD) & $\begin{array}{l}75.3 \\
(20.1)\end{array}$ & $71.0(17.1)$ \\
\hline $\begin{array}{l}\text { Time since diagnosed with SLE, } \\
\text { years, mean }(\mathrm{SD})\end{array}$ & $7.6(6.8)$ & $5.8(5.0)$ \\
\hline $\begin{array}{l}\text { Prednisone or equivalent daily } \\
\text { dosage, mg, mean (SD) }\end{array}$ & $\begin{array}{l}11.1 \\
(4.5)\end{array}$ & $11.2(4.9)$ \\
\hline \multicolumn{3}{|l|}{$\begin{array}{l}\text { Prednisone or equivalent daily } \\
\text { dosage, no. (\%) }\end{array}$} \\
\hline$\leq 20 \mathrm{mg} /$ day & $82(97.6)$ & $79(92.9)$ \\
\hline$>20 \mathrm{mg} /$ day & $2(2.4)$ & $6(7.1)$ \\
\hline Antimalarials, no. (\%) & $65(77.4)$ & $69(81.2)$ \\
\hline Immunosuppressants, no. (\%) & $62(73.8)$ & $47(55.3)$ \\
\hline $\begin{array}{l}\text { SLEDAI-2K total score [range } \\
0-105] \text {, mean }(S D)\end{array}$ & $\begin{array}{l}10.1 \\
(3.1)\end{array}$ & $9.7(3.0)$ \\
\hline $\begin{array}{l}\text { BILAG-2004 total score [range } \\
0-108], \text { mean }(S D)\end{array}$ & $\begin{array}{r}18.0 \\
(5.5)\end{array}$ & $18.2(5.2)$ \\
\hline PGA [range 0-100], mean (SD) & $\begin{array}{l}60.6 \\
\quad(16.7)\end{array}$ & $58.8(15.8)$ \\
\hline
\end{tabular}

Table 1 continued

\begin{tabular}{lcc}
\hline & $\begin{array}{l}\text { RCI } \\
(\boldsymbol{n}=\mathbf{8 4})\end{array}$ & $\begin{array}{c}\text { Placebo } \\
(\boldsymbol{n}=\mathbf{8 5})\end{array}$ \\
\hline $\begin{array}{l}\text { CLASI-Activity [range 0-70], mean } \\
\text { (SD) }\end{array}$ & $7.7(7.5)$ & $7.1(6.5)$ \\
28 SJC/TJC, mean (SD) & $7.9(5.9)$ & $7.2(5.0)$ \\
Complement C3 [range & 111.2 & 113.5 \\
90-180 mg/dl], mean (SD) & $(35.7)$ & $(31.3)$ \\
Complement C4 [range 10-40 mg/ & 19.5 & $18.7(9.5)$ \\
dl], mean (SD) & $(11.3)$ & \\
Anti-dsDNA antibody [range & 99.9 & 62.6 \\
$0-6.3$ IU/mL], mean (SD) & $(215.3)$ & $(165.2)$ \\
\hline
\end{tabular}

BILAG-2004 British Isles Lupus Assessment Group-2004, $C$ component, CLASI-Activity Cutaneous Lupus Erythematosus Disease Area and Severity Index-Activity, $d s D N A$ double-stranded deoxyribonucleic acid, $m I T T$ modified intention-to-treat, $P G A$ Physician's Global Assessment, $R C I$ repository corticotropin injection, $S D$ standard deviation, $S J C$ Swollen Joint Count, SLE systemic lupus erythematosus, SLEDAI-2K Systemic Lupus Erythematosus Disease Activity Index-2000, TJC Tender Joint Count

\section{RESULTS}

The trial was initiated on October 13, 2016, and was completed on October 25, 2019. Of 293 patients screened for eligibility, 172 were randomly assigned to treatment groups (Fig. 1). Of these, 86 were assigned to RCI, and 86 were assigned to placebo; 84 patients receiving RCI and 85 patients receiving placebo were included in the mITT population. At least $82.5 \%$ of patients in each treatment group completed the study. Of the patients who discontinued participation in the study, more patients in the placebo group $(n=5)$ discontinued because of disease progression than in the RCI group $(n=1)$.

The mITT population $(N=169)$ had a mean age of 39.7 years; patients were predominantly female $(91.7 \%)$, located outside of the US (66.9\%), and of Hispanic or Latino ethnicity $(80.5 \%)$. Most patients $(95.3 \%)$ were 


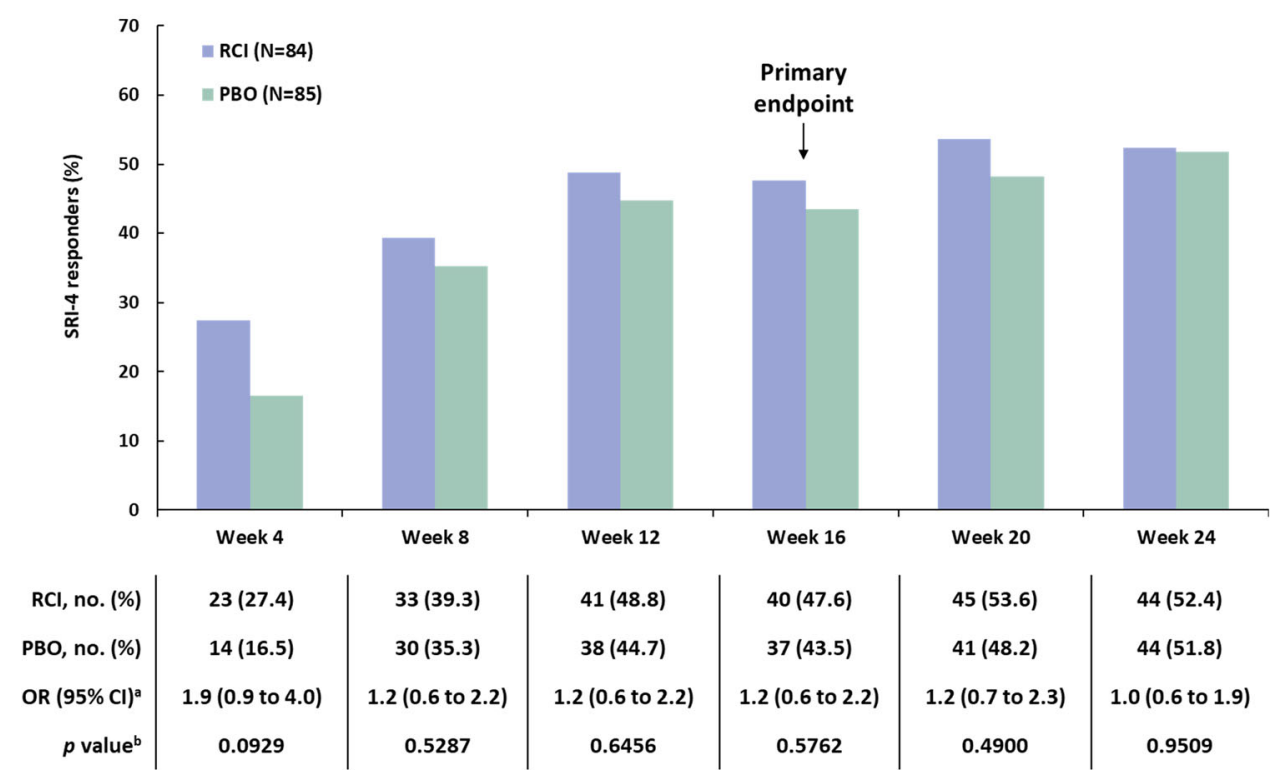

Fig. 2 SRI- 4 responders in the mITT population. ${ }^{a}$ The 95\% CI is asymptotic Wald confidence limits. ${ }^{\mathrm{b}}$ The $p$ values were assessed using a $\mathrm{CMH}$ test stratified for location (US and outside the US) and baseline glucocorticoid dose $(\leq 20$ and $>20 \mathrm{mg}$ per day). $C M H$

receiving $\leq 20 \mathrm{mg}$ of daily prednisone or equivalent glucocorticoid doses, and about half $(53.8 \%)$ of patients had baseline SLEDAI-2K scores $\geq 10$. Demographics and baseline disease characteristics for patients in each treatment group are presented in Table 1 . Patients randomized to receive RCI had a longer history of SLE diagnosis and higher levels of anti-dsDNA antibodies than patients who were randomized to placebo. More patients were receiving concomitant immunosuppressive therapy in the RCI group than in the placebo group.

The primary endpoint (the proportion of patients who achieved an SRI-4 response at week 16) was not significantly different between RCI and placebo (Fig. 2). Although there were more SRI-4 responders at all time points through week 24 in the RCI group than in the placebo group, no statistically significant differences between RCI and placebo were observed at any time point. All other $p$ values are nominal and are presented for information purposes only.

Patients who were treated with RCI showed greater reductions in $28 \mathrm{SJC} / \mathrm{TJC}$ and CLASI-
Cochran-Mantel-Haenszel, mITT modified intentionto-treat, $O R$ odds ratio, $P B O$ placebo, $R C I$ repository corticotropin injection. SRI-4 Systemic Lupus Erythematosus Responder Index-4

Activity scores at week 16 than patients receiving placebo (Table 2). Results for all other secondary endpoints were not different between RCI and placebo.

No differences were observed in exploratory endpoints related to changes in prednisone dose, proportion of SRI-4 responders, or patients with at least a four-point reduction in SLEDAI$2 \mathrm{~K}$ through week 24 in the RCI group (Figure S1 and Table S1 in the supplementary material). With the exception of BAFF, changes from baseline in levels of cytokines, circulating leukocytes, and bone turnover markers through week 24 for patients treated with RCI continue to be analyzed (Table S2 in the supplementary material). Patients who were treated with RCI showed greater reductions in levels of BAFF at week 8 (mean change: -327.4, SD 702.7; $p=0.0003$ for least square mean difference) than patients receiving placebo (mean change: 25.8, SD 554.7). Differences in the percent of baseline for BAFF were greater for patients treated with RCI than for patients treated with placebo at week 8 (Fig. 3). 
Table 2 Secondary endpoints in the mITT population

\begin{tabular}{|c|c|c|c|c|}
\hline & $\begin{array}{l}\text { RCI } \\
(n=84)\end{array}$ & $\begin{array}{l}\text { Placebo } \\
(n=85)\end{array}$ & $\begin{array}{l}\text { LS mean difference } \\
(95 \% \mathrm{CI})\end{array}$ & $p$ value $^{\mathrm{a}}$ \\
\hline $\begin{array}{l}\text { SLEDAI-2K [range 0-105] change from baseline at week 16, } \\
\text { mean (SD) }\end{array}$ & $\begin{array}{c}n=77 \\
-3.8 \\
(3.3)\end{array}$ & $\begin{array}{c}n=76 \\
-3.1 \\
(3.1)\end{array}$ & $\begin{array}{l}-0.5 \\
(-1.5 \text { to } 0.5)\end{array}$ & 0.3520 \\
\hline $\begin{array}{l}\text { BILAG-2004 [range 0-108] change from baseline at week 16, } \\
\text { mean (SD) }\end{array}$ & $\begin{array}{c}n=77 \\
-10.2 \\
(5.9)\end{array}$ & $\begin{array}{c}n=76 \\
-8.6 \\
(6.2)\end{array}$ & $\begin{array}{l}-1.6 \\
(-3.4 \text { to } 0.3)\end{array}$ & 0.0938 \\
\hline $\begin{array}{l}\text { PGA [range 0-100] change from baseline at week } 16 \text {, mean } \\
\text { (SD) }\end{array}$ & $\begin{array}{l}n=84 \\
-30.6 \\
(18.1)\end{array}$ & $\begin{array}{l}n=85 \\
-24.8 \\
(18.9)\end{array}$ & $\begin{array}{l}-4.1 \\
(-9.1 \text { to } 1.0)\end{array}$ & 0.1139 \\
\hline $\begin{array}{l}\text { CLASI-Activity [range 0-70] change from baseline at week } \\
16 \text {, mean (SD) }\end{array}$ & $\begin{array}{l}n=75 \\
-4.5 \\
(5.4)\end{array}$ & $\begin{array}{l}n=75 \\
-2.7 \\
(3.1)\end{array}$ & $\begin{array}{l}-0.9 \\
(-1.8 \text { to } 0.0)\end{array}$ & 0.0423 \\
\hline $\begin{array}{l}28 \text { SJC/TJC [range 0-28] change from baseline at week 16, } \\
\text { mean (SD) }\end{array}$ & $\begin{array}{c}n=75 \\
-6.4 \\
(5.7)\end{array}$ & $\begin{array}{c}n=75 \\
-4.2 \\
(3.8)\end{array}$ & $\begin{array}{l}-1.2 \\
(-2.3 \text { to }-0.2)\end{array}$ & 0.0203 \\
\hline Time to first SRI-4 response, days, median ( $95 \% \mathrm{CI}$ ) & $\begin{array}{l}n=84 \\
85 \\
(58.0 \text { to } \\
113.0)\end{array}$ & $\begin{array}{l}n=85 \\
86 \\
(81.0 \text { to } \\
136.0)\end{array}$ & NA & 0.6199 \\
\hline $\begin{array}{l}\text { Proportion of patients with } \geq 4 \text {-point reduction in SLEDAI- } \\
2 \mathrm{~K} \text { at week } 16 \text {, no. }(\%)\end{array}$ & $\begin{array}{l}n=84 \\
41(48.8)\end{array}$ & $\begin{array}{l}n=85 \\
40(47.1)\end{array}$ & NA & 0.8078 \\
\hline
\end{tabular}

ANCOVA analysis of covariance, BILAG-2004 British Isles Lupus Assessment Group-2004, CLASI-Activity Cutaneous Lupus Erythematosus Disease Area and Severity Index-Activity, $C M H$ Cochran-Mantel-Haenszel, $L S$ least square, $m I T T$ modified intention-to-treat, $N A$ not applicable, $P G A$ Physician's Global Assessment, $R C I$ repository corticotropin injection, $S D$ standard deviation, SJC Swollen Joint Count, SLEDAI-2K Systemic Lupus Erythematosus Disease Activity Index-2000, SRI-4 Systemic Lupus Erythematosus Responder Index-4, TJC Tender Joint Count

a Proportions of patients were analyzed using a CMH test stratified for location (US and outside the US) and baseline glucocorticoid dose ( $\leq 20$ and $>20 \mathrm{mg}$ per day). Quantitative endpoints were analyzed using ANCOVA models with the change from baseline as the dependent variable, treatment as the factor, and baseline value of the corresponding endpoint as the covariate and were stratified for location (US and outside the US) and baseline glucocorticoid dose ( $\leq 20$ and $>20 \mathrm{mg}$ per day). Time-to-response endpoints were analyzed using a log-rank test

A post hoc analysis applying the BICLA to the mITT population found a greater proportion of BICLA responders amongst those treated with RCI versus placebo at weeks 4,12 , and 20 (Fig. 4). At baseline, 47 patients $(56.0 \%$ of 84$)$ treated with RCI and 44 patients $(51.8 \%$ of 85$)$ treated with placebo had SLEDAI-2K $\geq 10$. In this subgroup, there were more SRI- 4 responders at all time points in the RCI group than in the placebo group, and a greater difference in the SRI-4 response rate for RCI versus placebo was noted at week 24 (Fig. 5a). At baseline, 22 patients $(26.2 \%$ of 84$)$ treated with RCI and 19 patients $(22.4 \%$ of 85$)$ on placebo had CLASI- 


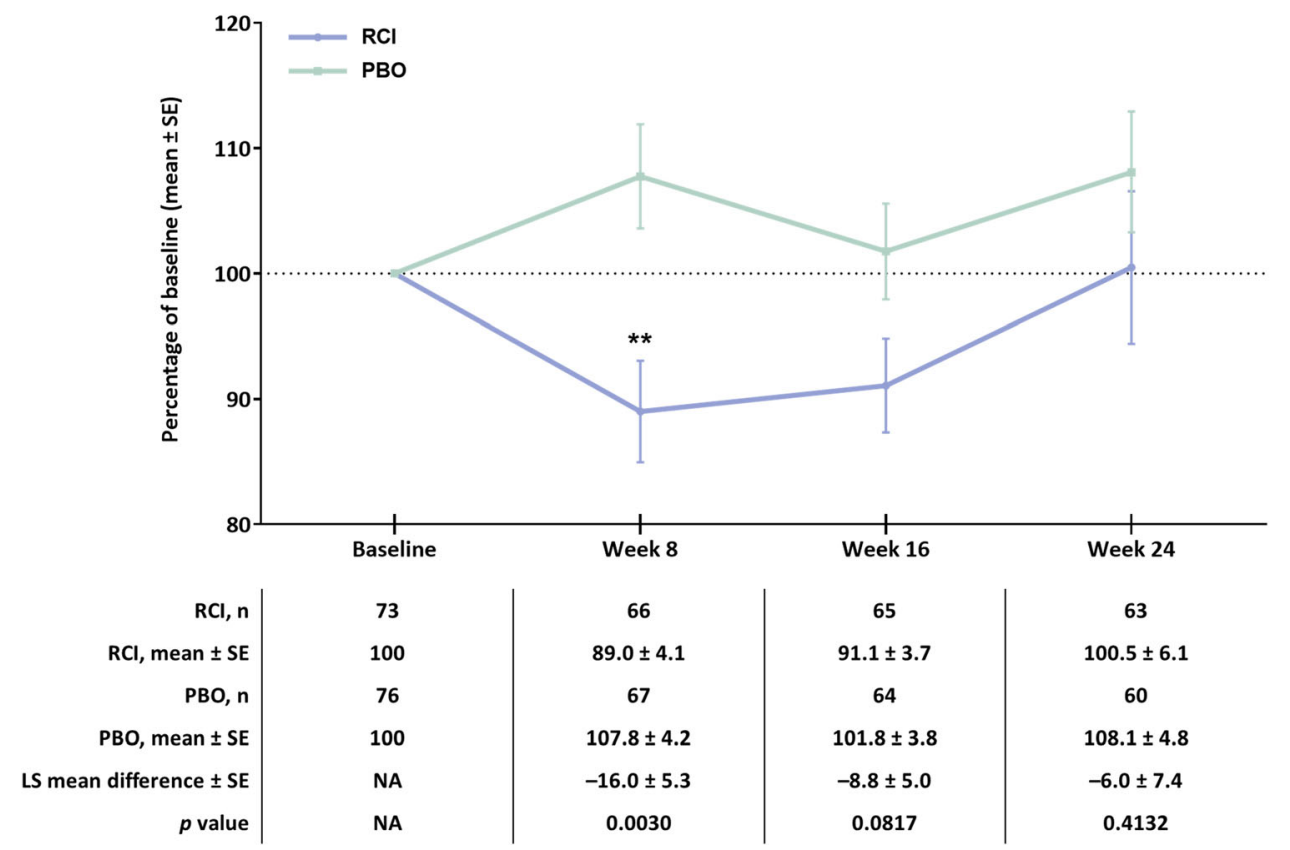

Fig. 3 Percentage of baseline over time for BAFF in the mITT population. ${ }^{* *} p<0.01$ for the LS mean difference using ANCOVA models with the change from baseline as the dependent variable, treatment as the factor, and baseline value of the corresponding endpoint as the covariate, with stratification for location (US and outside the US) and baseline glucocorticoid dose $(\leq 20$ and $>20 \mathrm{mg}$ per day). ANCOVA analysis of covariance, $B A F F$ B-cell activating factor, $L S$ least square, $m I T T$ modified intention-to-treat, $P B O$ placebo, $R C I$ repository corticotropin injection, $S E$ standard error

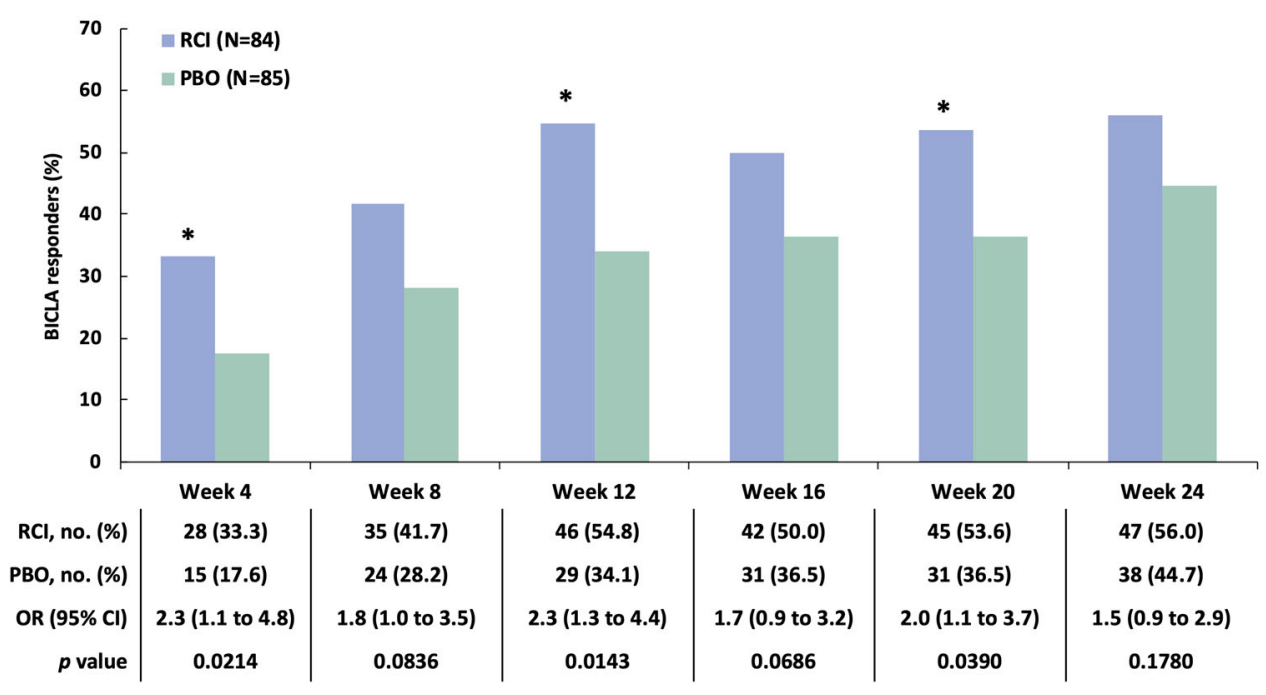

Fig. 4 BICLA responders in the mITT population. ${ }^{*} p<0.05$ from $\mathrm{CMH}$ test stratified for location (US and outside the US) and baseline glucocorticoid dose $(\leq 20$ and $>20 \mathrm{mg}$ per day). BICLA BILAG-Based
Combined Lupus Assessment, BILAG British Isles Lupus Assessment Group, $C M H$ Cochran-Mantel-Haenszel, mITT modified intention-to-treat, $O R$ odds ratio, $P B O$ placebo, $R C I$ repository corticotropin injection 
a

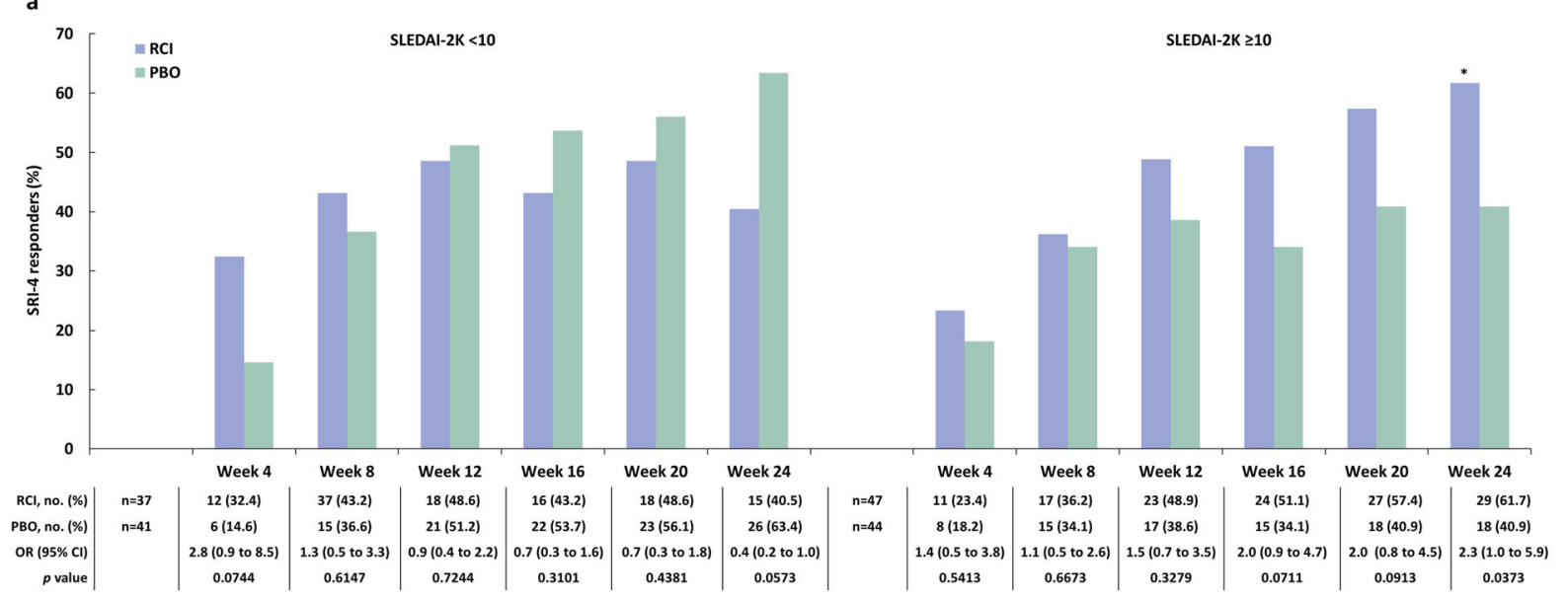

b

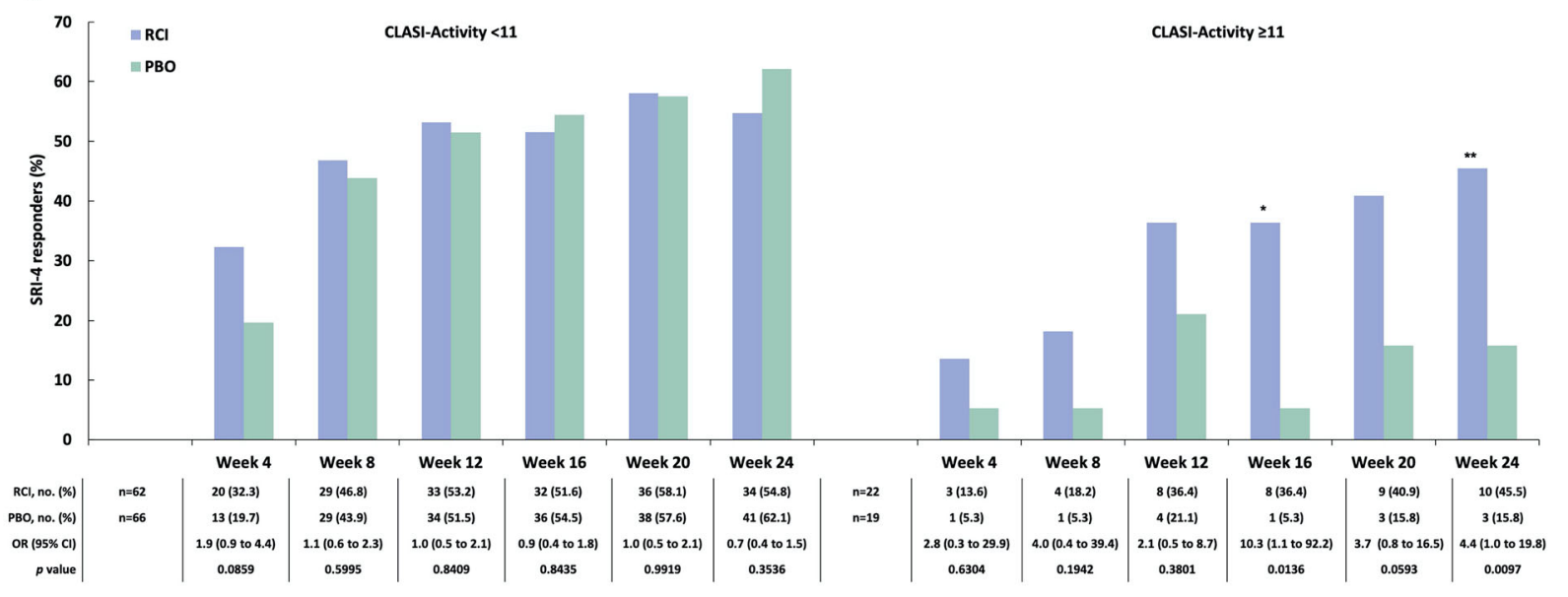

c

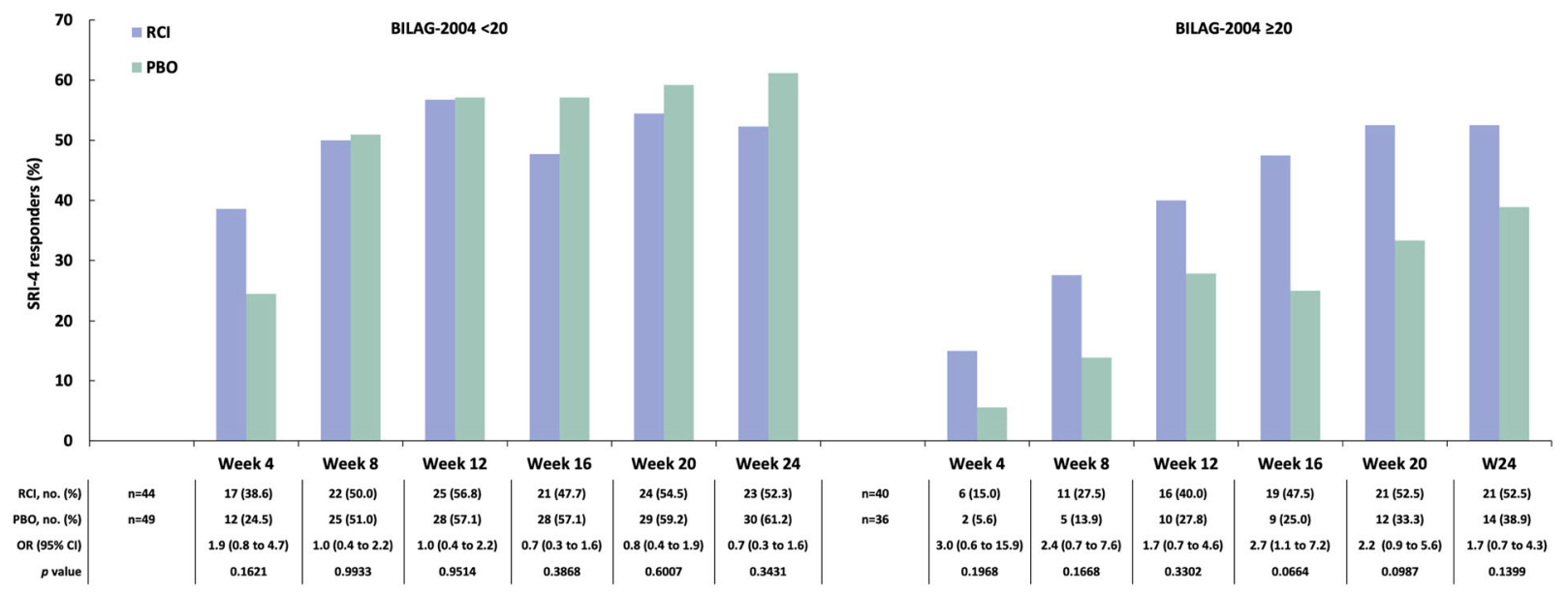


4Fig. 5 SRI-4 responders by baseline disease severity on the basis of SLEDAI-2K (a), CLASI-Activity (b), and BILAG2004 (c) scores in the mITT population ${ }^{*} p<0.05$; ${ }^{* *} p<0.01$ from CMH test stratified for location (US and outside the US) and baseline glucocorticoid dose $(\leq 20$ and $>20 \mathrm{mg}$ per day). BILAG-2004 British Isles Lupus Assessment Group-2004, CLASI-Activity Cutaneous Lupus Erythematosus Disease Area and Severity IndexActivity, CMH Cochran-Mantel-Haenszel, mITT modified intention-to-treat, $O R$ odds ratio, $P B O$ placebo, $R C I$ repository corticotropin injection, $S L E D A I-2 K$ Systemic Lupus Erythematosus Disease Activity Index-2000, SRI4 Systemic Lupus Erythematosus Responder Index-4

Activity $\geq 11$. In this subgroup, there were more SRI-4 responders at all time points in the RCI group than in the placebo group; greater differences in the SRI-4 response rate for RCI versus placebo were observed at week 16 and week 24 (Fig. 5b). Those with baseline BILAG$2004 \geq 20$ had numerically higher SRI-4 response rates (Fig. 5c). In the subgroup of patients who were screened and tested positive for ANA/anti-dsDNA/ENA antibodies at baseline, there were more SRI- 4 responders at all time points in the RCI group than in the placebo group. For those with historical autoantibody positivity unconfirmed by testing at screening, the difference in the SRI-4 response rate for RCI versus placebo was greater at only one time point, at week 4 (Fig. 6). In the subgroup of patients who had low complement $\mathrm{C} 4(<17 \mathrm{mg} / \mathrm{dl})$ at baseline, there were higher proportions of SRI- 4 responders at all time points in the RCI group than in the placebo group; a significantly greater difference in the SRI-4 response rate for RCI versus placebo was observed at week 20 (Fig. 7). Results for SRI-4 responders with ANA $\geq 1: 80$ at screening showed numerically higher response rates (data not shown).

In the safety population (RCI, $n=86$; placebo, $n=86$ ), more patients who were treated with RCI reported AEs than patients who were given placebo (Table 3). The most common AEs reported by patients who were treated with RCI included upper respiratory tract infection, insomnia, headache, hypertension, and urinary tract infection. Fewer patients in the RCI-treated group than in the placebo-treated group reported SAEs; these included SLE, herpes zoster, and nephrotic syndrome. The AEs of SLE, drug hypersensitivity, and nephrotic syndrome resulted in study discontinuation for RCI-

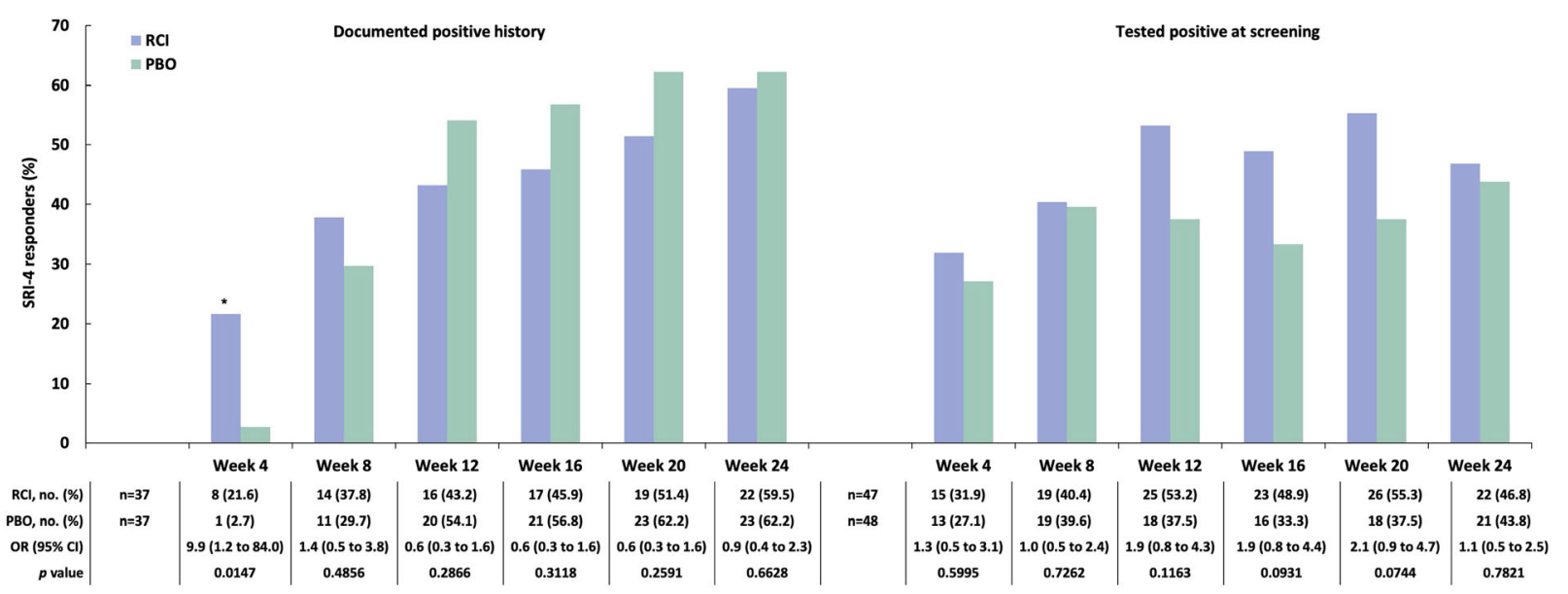

Fig. 6 SRI-4 responders by ANA/anti-dsDNA/ENA positivity at baseline in the mITT population. ${ }^{*} p<0.05$ from $\mathrm{CMH}$ test stratified for location (US and outside the US) and baseline glucocorticoid dose ( $\leq 20$ and $>20 \mathrm{mg}$ per day). $A N A$ antinuclear antibody, $C M H$
Cochran-Mantel-Haenszel, $d s D N A$ double-stranded deoxyribonucleic acid, ENA extractable nuclear antigen, mITT modified intention-to-treat, $O R$ odds ratio, $P B O$ placebo, $R C I$ repository corticotropin injection, SRI-4 Systemic Lupus Erythematosus Responder Index -4 


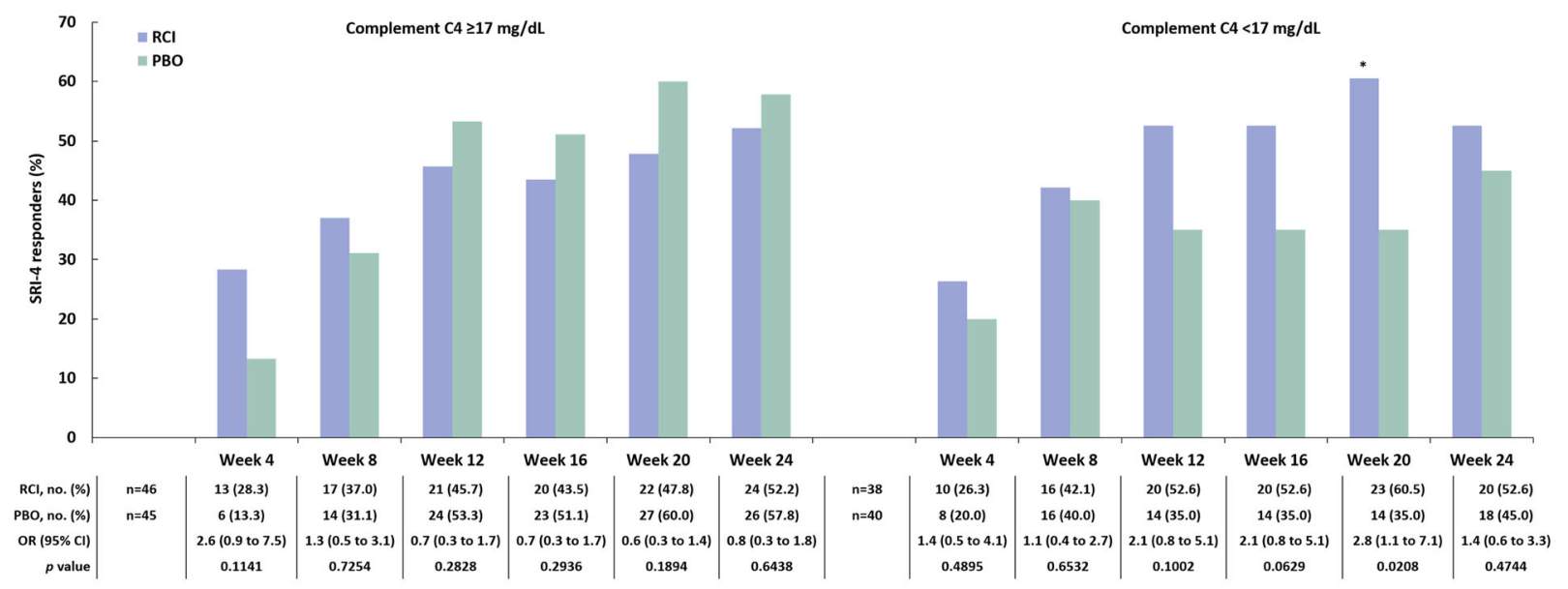

Fig. 7 SRI-4 responders by complement $\mathrm{C} 4$ results at screening in the mITT population. ${ }^{*} p<0.05$ from $\mathrm{CMH}$ test stratified for location (US and outside the US) and baseline glucocorticoid dose ( $\leq 20$ and $>20 \mathrm{mg}$ per day).

treated patients. One patient $(1.2 \%)$ in the placebo-treated group experienced an $\mathrm{AE}$ of drug abuse, which resulted in death; no AEs resulted in death in patients treated with RCI.

\section{DISCUSSION}

The study fell short of meeting its primary endpoint of the proportion of SRI-4 responders at week 16 after treatment with RCI. However, the study met two important secondary endpoints, including the change from baseline to week 16 in 28 SJC/TJC and CLASI-Activity scores in patients treated with RCI. Improvements in 28 SJC/TJC and CLASI-Activity after treatment with RCI are especially notable given that the study was enriched for patients with skin and joint manifestations at both screening and randomization. Additionally, at multiple time points, BICLA response rates were higher in the RCI treatment group. A greater SRI-4 response to RCI was observed in patients with higher baseline disease activity scores (SLEDAI$2 \mathrm{~K} \geq 10$; CLASI-Activity $\geq 11$ ) and in those with low complement $\mathrm{C} 4$ at baseline. No meaningful changes were observed in bone turnover markers. No consistent changes were observed in cytokine levels apart from BAFF. BAFF is known to be one of the key survival
$C$ component, $C M H$ Cochran-Mantel-Haenszel, $m I T T$ modified intention-to-treat, $O R$ odds ratio, $P B O$ placebo, $R C I$ repository corticotropin injection, SRI-4 Systemic Lupus Erythematosus Responder Index-4

factors for B lymphocytes that has potent stimulatory effects on B-cell proliferation and antibody production [23]. Furthermore, some changes were observed in the proportion of B-cell subsets among the circulating leukocytes; however, the clinical significance of these changes warrants further evaluation.

Notably, most patients in both treatment groups remained on stable glucocorticoid doses through the end of the study period despite the option of a glucocorticoid taper between weeks 16 and 24. All safety results were consistent with the known safety profile of RCI; no new safety signals were identified. AEs associated with glucocorticoids (e.g., hyperglycemia, hypertension) were more commonly reported by patients receiving RCI treatment than by those who were given placebo. Three patients (3.5\%) in the RCI-treated group reported AEs of hyperglycemia; all were women without a history of diabetes. However, two of these three patients were prediabetic at baseline. No patients in the placebo group reported hypoglycemia.

The measurement of SLE disease activity is challenging because of disease heterogeneity and the subjective nature of the evaluation [2]. Composite instruments, such as the SRI- 4 or the BICLA, are commonly used as endpoints in SLE 
Table 3 Safety results during the treatment period in the safety population

\begin{tabular}{|c|c|c|}
\hline & \multicolumn{2}{|c|}{ No. (\%) of patients } \\
\hline & $\begin{array}{l}\text { RCI } \\
(n=86)\end{array}$ & $\begin{array}{l}\text { Placebo } \\
(n=86)\end{array}$ \\
\hline Any adverse event & $61(70.9)$ & $55(64.0)$ \\
\hline \multicolumn{3}{|l|}{$\begin{array}{l}\text { Most common adverse events ( } \geq 39 \\
\text { group) }\end{array}$} \\
\hline $\begin{array}{l}\text { Upper respiratory tract } \\
\text { infection }\end{array}$ & $9(10.5)$ & $1(1.2)$ \\
\hline Insomnia & $7(8.1)$ & $4(4.7)$ \\
\hline Headache & $6(7.0)$ & $5(5.8)$ \\
\hline Hypertension & $6(7.0)$ & 0 \\
\hline Urinary tract infection & $6(7.0)$ & $10(11.6)$ \\
\hline Herpes zoster & $4(4.7)$ & 0 \\
\hline Influenza & $4(4.7)$ & $2(2.3)$ \\
\hline Nasopharyngitis & $3(3.5)$ & $6(7.0)$ \\
\hline Urticaria at the injection site & $3(3.5)$ & $1(1.2)$ \\
\hline Bronchitis & $3(3.5)$ & 0 \\
\hline Hyperglycemia & $3(3.5)$ & 0 \\
\hline Nausea & $2(2.3)$ & $3(3.5)$ \\
\hline Gastroenteritis & $1(1.2)$ & $3(3.5)$ \\
\hline Serious adverse events & $4(4.7)$ & $8(9.3)$ \\
\hline Systemic lupus erythematosus ${ }^{\mathrm{a}}$ & $2(2.3)$ & $1(1.2)$ \\
\hline Herpes zoster & $1(1.2)$ & 0 \\
\hline Nephrotic syndrome & $1(1.2)$ & 0 \\
\hline Appendicitis & 0 & $1(1.2)$ \\
\hline Drug abuse & 0 & $1(1.2)$ \\
\hline Gastroenteritis & 0 & $1(1.2)$ \\
\hline Peritonitis & 0 & $1(1.2)$ \\
\hline Pneumonia & 0 & $1(1.2)$ \\
\hline Pyelonephritis & 0 & $1(1.2)$ \\
\hline Soft tissue infection & 0 & $1(1.2)$ \\
\hline $\begin{array}{l}\text { Adverse events leading to study } \\
\text { discontinuation }\end{array}$ & $4(4.7)$ & $3(3.5)$ \\
\hline
\end{tabular}

Table 3 continued

\begin{tabular}{lll}
\hline & \multicolumn{2}{l}{ No. (\%) of patients } \\
\cline { 2 - 3 } & $\begin{array}{l}\text { RCI } \\
(\boldsymbol{n}=\mathbf{8 6})\end{array}$ & $\begin{array}{l}\text { Placebo } \\
(\boldsymbol{n}=\mathbf{8 6})\end{array}$ \\
\hline Systemic lupus erythematosus $^{\mathrm{a}}$ & $2(2.3)$ & 0 \\
Drug hypersensitivity $_{\text {Nephrotic syndrome }}$ & $1(1.2)$ & 0 \\
Drug abuse & $1(1.2)$ & 0 \\
Hemolytic anemia & 0 & $1(1.2)$ \\
Pneumonia & 0 & $1(1.2)$ \\
Adverse events resulting in death & 0 & $1(1.2)$ \\
Drug abuse & 0 & $1(1.2)$ \\
\hline
\end{tabular}

$R C I$ repository corticotropin injection, $S L E$ systemic lupus erythematosus

a Indicates SLE flare or SLE exacerbation

clinical trials. The SRI-4 incorporates the SLEDAI-2K as the main measure of improvement. Because SLEDAI-2K response can be achieved only if a manifestation resolves, it is not sensitive to partial improvement. In contrast, BICLA relies on the BILAG as its central disease activity measure and can therefore capture partial improvements in disease activity. The BICLA appears to be more specific to multiorgan improvements than the SRI-4. As discordance between BICLA and SRI has recently been encountered in other SLE clinical trials [24, 25], we performed a post hoc analysis evaluating BICLA responses.

This study has several limitations. Enrollment of restricted ethnicity ( $>80 \%$ Hispanic or Latino ethnicity) may limit the application of these results to the general SLE population. Additionally, documented historical ANA/antidsDNA/ENA positivity was allowed rather than confirming the presence of these antibodies through testing at study entry. Further, patients were permitted to continue using stable doses of standard SLE therapy (i.e., NSAIDs, antimalarials, glucocorticoids, methotrexate, azathioprine, and mycophenolate mofetil) during the study period. 


\section{CONCLUSIONS}

Treatment with $80 \mathrm{U}$ of RCI twice weekly for up to 24 weeks was associated with improvements in two secondary endpoints (28 SJC/TJC and CLASI-Activity scores at week 16) in patients with persistently active SLE despite use of moderate-dose glucocorticoids. Greater benefits of RCI were also observed in post hoc analyses of SRI-4 response in the subgroup of patients with higher levels of SLE disease activity. Similar to findings of a recent anifrolumab trial [24], treatment with RCI resulted in a greater number of BICLA responders than with placebo at weeks 4,12 , and 20 despite a lack of difference in treatment response when measured by the SRI4. The advantage of RCI observed with BICLA for the entire population, in concert with the benefits observed with SRI-4 in the subsets of patients with higher levels of disease activity, support the potential utility of RCI in the treatment of active SLE with SLEDAI-2K scores $\geq 10$, CLASI-Activity scores $\geq 11$, BILAG-2004 scores $\geq 20, \quad$ and complement C4 levels $<17 \mathrm{mg} / \mathrm{dl}$.

\section{ACKNOWLEDGEMENTS}

We thank the participants of the study.

Funding. Sponsorship for this study and Rapid Service Fee were funded by Mallinckrodt Pharmaceuticals.

Medical Writing and Editorial Assistance. Professional writing and editorial support were provided by Amber Watson, PharmD, of MedLogix Communications, LLC, Itasca, Illinois, under the direction of the authors and was funded by Mallinckrodt Pharmaceuticals.

Authorship. All named authors meet the International Committee of Medical Journal Editors (ICMJE) criteria for authorship for this article, take responsibility for the integrity of the work as a whole, and have given their approval for this version to be published.
Prior Presentation. This manuscript is based on work previously presented in part at the European Congress of Rheumatology in Madrid, Spain (June 12-25, 2019) and the American College of Rheumatology Annual Meeting in Atlanta, Georgia (November 8-13, 2019). These data have also been accepted for future presentation at the Congress of Clinical Rheumatology-West Virtual Congress (October 8-11, 2020).

Disclosures. Anca D. Askanase and Richard A. Furie have nothing to disclose. Enxu Zhao, Julie Zhu, and Roman Bilyk are current employees of Mallinckrodt Pharmaceuticals. Enxu Zhao and Julie Zhu are current shareholders of Mallinckrodt Pharmaceuticals.

Compliance with Ethics Guidelines. The study protocol was approved by the Western Institutional Review Board centrally and by the local ethics committees/institutional review boards at individual study sites. The study was conducted in accordance with the Declaration of Helsinki and requirements of clinical trials registration (ClinicalTrials.gov identifier NCT02953821). Written informed consent from patients was required.

Data Availability. The datasets generated during and/or analyzed during the current study are not publicly available. Individual patient data may be requested if allowed per informed consent and appropriately anonymized. Requests should be sent to Mallinckrodt Pharmaceuticals' department for Clinical Trial Disclosure and Transparency at clinicaltrials@mnk.com.

Open Access. This article is licensed under a Creative Commons Attribution-NonCommercial 4.0 International License, which permits any non-commercial use, sharing, adaptation, distribution and reproduction in any medium or format, as long as you give appropriate credit to the original author(s) and the source, provide a link to the Creative Commons licence, and indicate if changes were made. The images or other third party material in this article are included in the article's 
Creative Commons licence, unless indicated otherwise in a credit line to the material. If material is not included in the article's Creative Commons licence and your intended use is not permitted by statutory regulation or exceeds the permitted use, you will need to obtain permission directly from the copyright holder. To view a copy of this licence, visit http:// creativecommons.org/licenses/by-nc/4.0/.

\section{REFERENCES}

1. Tsokos GC. Systemic lupus erythematosus. N Engl J Med. 2011;365(22):2110-211.

2. Hruskova Z, Tesar V. Lessons learned from the failure of several recent trials with biologic treatment in systemic lupus erythematosus. Expert Opin Biol Ther. 2018;18(9):989-96.

3. Fanouriakis A, Kostopoulou M, Alunno A, et al. 2019 update of the EULAR recommendations for the management of systemic lupus erythematosus. Ann Rheum Dis. 2019;78(6):736-45.

4. Acthar Gel [package insert]. Bedminster, NJ: Mallinckrodt ARD LLC; 2019.

5. Catania A, Lonati C, Sordi A, Carlin A, Leonardi P, Gatti S. The melanocortin system in control of inflammation. Sci World J. 2010;10:1840-53.

6. Ahmed TJ, Montero-Melendez T, Perretti M, Pitzalis C. Curbing inflammation through endogenous pathways: focus on melanocortin peptides. Int J Inflam. 2013;2013:985815.

7. Caruso C, Carniglia L, Durand D, Scimonelli TN, Lasaga M. Astrocytes: new targets of melanocortin 4 receptor actions. J Mol Endocrinol. 2013;51(2): R33-50.

8. Decker DA, Grant C, Oh L, Becker PM, Young D, Jordan S. Immunomodulatory effects of H.P. Acthar Gel on B cell development in the NZB/W F1 mouse model of systemic lupus erythematosus. Lupus. 2014;23(8):802-12.

9. Montero-Melendez T. ACTH: the forgotten therapy. Semin Immunol. 2015;27(3):216-26.

10. Fiechtner JJ, Montroy T. Treatment of moderately to severely active systemic lupus erythematosus with adrenocorticotropic hormone: a single-site, open-label trial. Lupus. 2014;23(9):905-12.
11. Furie R, Mitrane M, Zhao E, Das M, Li D, Becker PM. Efficacy and tolerability of repository corticotropin injection in patients with persistently active SLE: results of a phase 4 , randomised, controlled pilot study. Lupus Sci Med. 2016;3(1):e000180.

12. Furie RA, Mitrane M, Zhao E, Becker PM. Repository corticotropin injection in patients with persistently active SLE requiring corticosteroids: post hoc analysis of results from a two-part, 52-week pilot study. Lupus Sci Med. 2017;4(1):e000240.

13. Askanase $\mathrm{AD}$, Zhao E, Zhu J, Connolly-Strong E, Furie RA. Acthar Gel (repository corticotropin injection) for persistently active systemic lupus erythematosus: study design and baseline characteristics from a multicenter, randomized, doubleblind, placebo-controlled trial. Lupus Sci Med. 2020;7(1):e000383.

14. Hochberg MC. Updating the American College of Rheumatology revised criteria for the classification of systemic lupus erythematosus. Arthritis Rheum. 1997;40(9):1725.

15. Gladman DD, Ibañez D, Urowitz MB. Systemic lupus erythematosus disease activity index 2000. J Rheumatol. 2002;29(2):288-91.

16. Isenberg DA, Rahman A, Allen E, et al. BILAG 2004. Development and initial validation of an updated version of the British Isles Lupus Assessment Group's disease activity index for patients with systemic lupus erythematosus. Rheumatology (Oxford). $2005 ; 44(7): 902-6$.

17. Klein RS, Morganroth PA, Werth VP. Cutaneous lupus and the Cutaneous Lupus Erythematosus Disease Drea and Severity Index instrument. Rheum Dis Clin N Am. 2010;36(1):33-51 (vii).

18. Petri M, Buyon J, Kim M. Classification and definition of major flares in SLE clinical trials. Lupus. 1999;8(8):685-91.

19. Buyon JP, Petri MA, Kim MY, et al. The effect of combined estrogen and progesterone hormone replacement therapy on disease activity in systemic lupus erythematosus: a randomized trial. Ann Intern Med. 2005;142(12 Pt 1):953-62.

20. Yee CS, Cresswell L, Farewell V, et al. Numerical scoring for the BILAG-2004 index. Rheumatology (Oxford). 2010;49(9):1665-9.

21. Furie RA, Petri MA, Wallace DJ, et al. Novel evidence-based systemic lupus erythematosus responder index. Arthritis Rheum. 2009;61(9):1143-51.

22. Wallace DJ, Strand V, Furie R, et al (2011) Evaluation of treatment success in systemic lupus erythematosus clinical trials: development of the British 
Isles Lupus Assessment Group-based composite lupus assessment endpoint. Presented at: ACR: Poster 2265

23. Mackay F, Schneider P. Cracking the BAFF code. Nat Rev Immunol. 2009;9(7):491-502.

24. Furie RA, Morand EF, Bruce IN, et al. Type I interferon inhibitor anifrolumab in active systemic lupus erythematosus (TULIP-1): a randomised, controlled, phase 3 trial. Lancet Rheumatol. 2019;1(4):e208-e219.

25. van Vollenhoven RF, Hahn BH, Tsokos GC, et al. Efficacy and safety of ustekinumab, an IL-12 and IL23 inhibitor, in patients with active systemic lupus erythematosus: results of a multicentre, doubleblind, phase 2, randomised, controlled study. Lancet. 2018;392(10155):1330-9. 